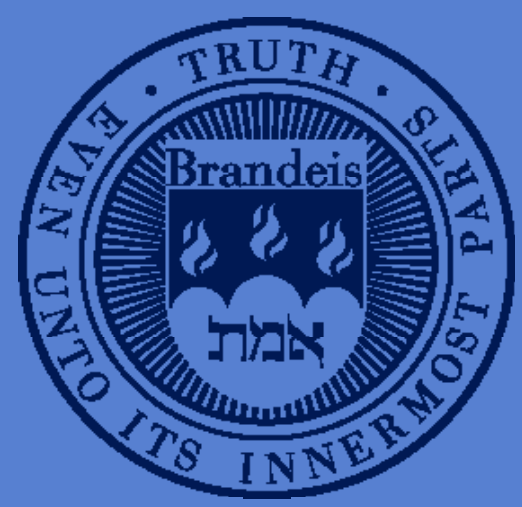

\title{
The role of research and ownership collaboration in generating patent quality: China-U.S. comparisons
}

Gary H. Jefferson and Sam Zucker, Economics Department, Brandeis University

Renai Jiang, Xi'an Jiaotong University

Lintong Li, Princeton University

Working Paper Series 


\title{
The role of research and ownership collaboration in generating patent quality: China-U.S comparisons*
}

\author{
Renai Jiang, Xi'an Jiaotong University \\ Gary H. Jefferson and Sam Zucker, Brandeis University \\ Lintong Li, Princeton University
}

November 28, 2017

Draft: For review and comment only

\begin{abstract}
This paper uses patent data from the U.S. Patent and Trademark Office to investigate the implications of inventor collaboration and joint assignee ownership, both domestic and international, on patent quality as measured by the number of claims and citations associated with a patent. Specifically, we compare the quality implications of research collaboration and joint ownership for the quality of U.S. and Chinese patents. Overall, we find that domestic inventor collaboration yields higher quality results for U.S. patents than Chinese patents. However, for China, international collaboration, both for inventors and assignee ownership is associated with higher quality outcomes for Chinese patents than for U.S. patents. We also find that the incidence of inventors sharing assignee ownership is significantly higher in China. We hypothesize that this difference reflects a need in China to extend patent ownership to inventors for the purpose of recruiting and incentivizing a relatively limited supply of high-quality researchers, whereas in the U.S. the abundance of such researchers is retained largely through wage and bonus compensation.
\end{abstract}

\footnotetext{
*Acknowledgements: Project of National Natural Science Foundation of China "The Transfer Mechanism and Impact of International Direct R\&D Spillovers on Technological Progress in China (71302147)".
} 


\section{Introduction}

By any measure, China's surge in national resources devoted to S\&T development and the outcomes therefrom is likely without precedent. Whereas the U.S. has had more than 200 years of a continuous patent law and IPR enforcement, China only reestablished its patent law in 1985. Thereafter, over the recent two decades, China's RD/GDP ratio rose from just $0.6 \%$ in 1996 to over $2 \%$, a level comparable to that of the major innovators in the OECD. In 2015 more than a million patents were filed in China's patent office, the State Intellectual Property Office, more than those filed in any other country. ${ }^{1}$ A central objective of this paper is to evaluate the quality of China's patent production relative to that of the U.S. and to assess the factors that determine patent quality in both countries, including the terms of trade or contribution that China, the U.S. and the innovation systems of other countries make to overall patent quality. Recent studies, reviewed in the following section, have concluded that the role of team research has grown substantially in generating successful innovation outcomes. In this paper, we attempt to distinguish the contributions to patent quality of domestic collaboration versus that of collaboration across countries. Toward this end, we utilize three measures of patent quality: backward citations, claims, and forward citations. We further investigate the role of patterns of patent ownership assignment, i.e., the assignees, as such patterns affect the above measures of patent quality. Our data further enable us to investigate the role of different types of organizations - firms, universities, and research institutes - as their participation in the innovation process affects patent quality.

Our research objectives include the following:

Profile and evaluate the evolution of the quantity and quality of Chinese patents vs. those of the U.S.

Analyze the impact of research collaboration and patent ownership on patent quality, by evaluating the implications of the following for patent quality:

- The number of inventors;

- The internationalization of inventor teams;

\footnotetext{
${ }^{1}$ Actually, in 2016, 2 million were filed but only 1,025,000 of these were of the highest quality "invention" patents eligible for 20 year patent duration. The balance were utility and design patents eligible for only 10 years of patent protection.
} 
- As with inventors, the number and internationalization of assignee ownership;

- Also the institutional affiliation of assignees across corporations, universities, and inventors, both domestic and international; and

- The distribution of assignees across inventors, i.e., the incentive effect or the scale effect represented by the assignee-inventor relationship.

Our key findings fall into three areas. The first is that domestic collaboration in the U.S. yields higher returns to patent quality than equivalent team research in China. On the other hand, the quality advantages of international inventor collaboration for Chinese patents are substantially greater than those accruing to U.S. patents, which appear to be negligible or even negative. These finding are confirmed by our analysis of four specific industries: automobiles, pharmaceuticals, semi-conductors, and solar energy.

The second key finding relates to the assignment of patent ownership. While the finding regarding less positive outcomes for domestic collaboration for China than the U.S. and more positive outcomes for international joint assignees for China than the U.S. are not as robust for assignees as for inventors, they are nonetheless differentiated similarly. Finally, we construct various ratios of assignees to inventors, proposing that high ratios leading to higher quality outcomes reflect positive incentive effects of a higher proportion of inventors enjoying assignee ownership rights whereas a low ratio implies the presence of scale effects, i.e., relatively large numbers of inventors per assignee may be indicative of substantial scale advantages. Our results suggest the presence of incentive effects for Chinese patenting, whereas for the U.S., the quality advantage appears to result from scale effects.

The following section reviews the relevant literature. Section 3 introduces the data. Section 4 describes the patent quality. Section 5 focuses on inventions. Section 6 focuses on assignees. Section 7 focuses on the assignee/inventor ratio. Section 8 interprets certain of the more puzzling results. Section 9 concludes.

\section{Literature Review}

Wuchty, Jones, and Uzzi (2007) have produced a particularly relevant piece of research. Reviewing 19.9 million papers distributed over 5 decades and 2.2 million patents, they 
demonstrate that increasingly, overtime, teams have come to dominate solo authors in the production of knowledge. Their specific findings include the following:

Research is increasingly done in teams across nearly all fields. Teams typically produce more frequently cited research than individuals; this advantage has been increasing over time.

$>$ Whereas sole authors were once mostly associated with the highest-impact research, this is now largely produced in team settings; and

$>$ These results suggest that the process of knowledge creation has fundamentally changed. Wutchy and his colleagues use a measure they call the "relative team index" (RTI) to evaluate the relative quality of research outcomes. The RTI is the mean number of citations received by team-authored work divided by the mean number of citations received by soloauthored work. An RTI > 1indicates that teams produce more highly cited papers than solo authors for which RTI $<1$. When the RTI $=1$, there is no difference in citation rates for team and solo-authored papers.

Mowery and Sampat (2009) and Ankrah and AL-Tabbaab (2015) contribute to and review the growing literature that focuses on universities as important sources of fundamental knowledge and their growing interaction with industry in creating jointly funded and staffed labs resulting in joint patent outcomes. These authors explain how, since the 1970s, governments throughout the industrialized economies have launched numerous initiatives to promote close links between universities and industrial innovation, resulting, in particular, in an expanded role of universities in applied innovation has.

A closely related conceptual framework for analyzing the changing position of universities within national innovation systems is the "Triple Helix" model popularized by Etzkowitz and Leydesdorff (2000). This model was proposed as an attempt to understand the shift from an industry-government dyadic system in the industrial society to a growing university-industry-government triadic one in the knowledge society. Interestingly, related research also reveals avenues through which corporate-university research collaboration may impede research productivity.

Soh and Subramanian (2014), for example, find evidence that suggests that increasing the overlap in resources and expertise between firms and universities can lead to knowledge redundancy and coordination expenses, which can reduce the expected social returns from 
university-industry collaborations. Maietta (2015) also suggests that the expected returns from university-industry collaboration may be reduced because university scholars may actively collaborate with firms only on topics that are relevant for their academic career advancement.

We seek both to extend and specialize the assessment of team research and interorganizational collaboration in the following ways:

$>$ We focus only on patents with the special purpose of examining the complementarity and exchange of intellectual property between China and the U.S. extending our sample period from to $1975-2015$.

$>$ As well as forward citations, we use backward citations and claims as measures of patent quality.

$>$ In addition to evaluating the impact of team research generally, we distinguish between the contribution of domestic and international team work.

$>$ We also examine the impact of patent ownership, as represented by assignee designations.

$>$ Furthermore, unlike Wutchy et al (2007), we use continuous measures of team collaboration and regression analysis to evaluate the relationship between various configurations of inventor and assignee collaboration and patent quality.

In the following section, we profile the extent to which the Chinese inventors, as compared with U.S. inventors, have engaged with multiple inventors and assignees, domestic and international, for the purpose of producing successfully granted patents.

\section{Background data}

In principle, to conduct this study, we had the choice of using data from the Chinese State Intellectual Property Office (SIPO) rather than the USPTO. To help resolve this matter, Table 1 reports comparative SIPO-USPTO data. We see that in recent years, whereas the total patent volume in SIPO has been considerably larger than that of the U.S., the patent count for approved higher-quality invention patents has been comparable or China and the U.S. For purposes of this study, we choose to use the USPTO data base for the following reasons:

$>$ Whereas approximately one-half of U.S. patents originate with foreign residents, the proportion for China is only about one-quarter. 
While the relevant patent counts for SIPO and the U.S. for 2015 are similar, for the purpose of extending the analysis to 1995 or earlier, the number of patents granted by SIPO, particularly those from abroad, is a relatively small number. In 1995, only 45,064 patents in total, of which just 3,393 were invention patents, were granted by SIPO, of which 3,816, including 1,863 invention patents, were from abroad. By comparison, in 1995, 101,419 utility patents were granted by the USPTO, of which 55,909, more than half, were from abroad.

$>$ Patents that are approved by the USPTO are likely to represent a higher, more uniform level of quality than those granted by SIPO.

$>$ Finally, of particular consequence for this research project, the USPTO includes the name and address for each assignee and inventor as well as the organizational affiliation of each assignee. By comparison, while SIPO also reports the name of each assignee, it only reports the address of the first assignee.

Table 2 shows the USPTO patent count by national origin. It is important to recognize that the USPTO does not designate a patent by national origin per se. It reports the name and address of the inventors associated with each incoming patent application. Once the USPTO has decided to grant a patent, the patent file also designates each of the assignees, their names and addresses, and their organizational affiliations. For the purpose of our research, we designate the national origin of a patent by the addresses of the inventors or assignees. When we analyze the impact of international inventor collaboration on patent quality, whether a patent is "international" or not is determined by the addresses of the listed inventors. When we analyze the impact of joint international assignee status on patent quality, likewise, the international status of the patent is determined by the addresses of the various assignees. Hence a single patent bearing both U.S. and Chinese addresses may be treated as an international patent from the U.S. perspective and as an international patent from the Chinese perspective.

Using the method above, Table 2 shows the number of approved patents by national origin for 1990, 2000, 2010, and 2015. The table shows substantial increases in patent counts for the U.S., China, Japan, S. Korea, German, and the other European Countries together. While even that for the U.S. rose more than four-fold over the reported 25-year period, having started from a low base, China and S. Korea show by far the most dramatic patent surges. 
Using the USPTO data, Table 3 shows for China, the U.S., Japan, S. Korea, Germany, and other EU countries, the change in research and ownership collaboration from the earlier period, 1975-2005 to 2006-2015. For all the countries, with the exception of Japan, the average number of inventors rose from the earlier to the later period; the U.S., Germany, and the other EU countries show the share of their patents with inventor collaboration more than doubling from the earlier to the later period. China, exhibiting by far the highest share of international collaboration for patents granted in 1997-2005 and 2006-2015, shows no increase from the earlier to the later period. Regarding assignees, Table 3 shows that the incidence of multiple assignees is much smaller than that of inventors; moreover, only China shows more than a $10 \%$ increase in the number of assignees from the earlier to the later period. Table 3 also shows that the same countries that exhibited a doubling in their incidences of assignee collaboration were the same that had reported similar increases in international inventor collaboration from the earlier to the later periods. Again, as with international inventor collaborations, China stands out as the country with the largest number of international assignee collaborations. For China, however, the curious feature is that whereas the country reported a dramatic increase in assignee collaborations, it shows no increase at all in the share of international inventor collaborations.

4. Modeling patent quality, data, model specifications

We utilize the following three measures of patent quality.

Backward citations. As part of the patent filing, patent applications are required to cite prior research and inventions - both publications and patents - that provide the backdrop for the invention under review. Table 4 shows comparisons of the average number of backward citations associated with each country's portfolio of patent grants. While the U.S. holds a margin in 1990 and 2000 of nearly 2 to 1, the data show a puzzling surge in backward citations from 2010 and 2015. While of the countries increase their backward citation counts from 2000 to 2015 that for the U.S. stands out as particularly noticeable, elevating the U.S. count by more than a factor of 3. At the same time, the counts for the other countries jump significantly by two- to three-fold.

Noting and analyzing this dramatic increase in backward patent citations since 2000, Jaffe and de Rassenfosse (2017) conclude that the surge has been "...facilitated by digitization of 
the patent data and increasing computing power." Their explanation may or may not entirely account for the surge in the number of backward citations, but it is certainly a factor. Insofar as the patent regulations require that each claim on the patent be linked to one or more backward citations, we might anticipate that as a driver of backward citations, the number of claims may have also shown a significant increase over the $2000-2015$ period. In fact, contrary to this expectation, Table 5 shows that, with the exception of China, none of the countries shows a notable increase in the number of claims. As with Jaffe and de Rassenfosse (2017), we attribute the post-2000 surge in backward citations post-2000 to the ubiquitous use of the digitization and internet in compiling research data.

Claims: The number of claims awarded a patent are a proxy for the breadth of the patent. According to Hall, Jaffe, and Trajtenberg (2001, pp. 23-24):

The claims specify in detail the "components", or building blocks of the patented invention, and hence their number may be indicative of the "scope" or "width" of the invention.

The breadth of a patent relates to the number of technology classifications that it spans. Table 5 shows that in 2015, the average U.S. patent recorded the largest number of claims. China was 5 fewer, little more than two-thirds the average number of claims for a U.S. patent. Nonetheless, the average number of claims for a Chinese patent was greater in 2015 than those recorded for its counterpart average Japanese patent.

Conducting a study of the relative number of claims of patents filed with SIPO originating with Chinese residents versus overseas residents, Song and Li (2014) find that in 2012 while the average number of claims for patents from developed countries was 22, the average number for Chinese patents was only six. This large disparity confirms that our focus on only those patents granted by the USPTO results in a comparison of the very highest quality Chinese patents for which the average number of claims for the 2010-2015 period is 12 vs. 18 for the U.S.

As with the distribution of backward citations shown in Fig. 1, Fig. 2 shows that the distribution of claims conforms with a Poisson distribution. The somewhat unusual feature of the distribution is that the histogram shows that the claim count for 20 is a multiple of the 
numbers for 19 and 21. We infer that that spike results from the fact of USPTO guidelines that require a supplemental fee for patent filings that include more than 20 claims.

Forward citations: Forward citations have become a popular measure of patent quality, as the measure is for the quality of academic publications. Hall, Jaffe, and Trajtenberg (2005) test the economic significance of forward citations using Tobin's q hedonic regression equations for three properties of each of the firms in its sample of U.S. publicly-traded firms. The three firm-specific innovation-related characteristics are: i) R\&D intensity, ii) The R\&D yield in terms of the ratio of the patent count to the firm's R\&D stock, and iii) the average number of forward patents for the firm's patent portfolio. The authors find that each of these measures, forward citations included, has a positive and significant impact on the firm's Tobin q.

Reporting on forward citations, Table 6 shows a dramatic dropoff in the number of citations after 2000. This, unsurprising truncated distribution, is due to the forward nature of such citations. Forward citations do not begin to accumulate until after the patent has been filed. This condition is particularly disadvantageous for the China forward citation count given that its patent count surged only after 2000. Hall et al (2005) control for this condition by estimating the shape of the citation lag distribution. We control for the lag effect using year dummies.

As with backward citations and claims, we find that the distribution of forward claims follows a Poisson distribution. Hence, as with backward citations and claims, we use a Poisson estimator to analyze the implications of various forms of inventor and ownership collaboration for patent quality.

\section{Invention Collaboration}

We first test the implications of team research measured in terms of two conditions: i) the number of inventors cited in the patent grant and whether or not an international inventor, meaning one with a foreign address, was included in the patent filing. To test the impact of the number of inventors and the internationalization of the patent research, we use the following regression equation:

$$
\operatorname{lnPAT}(1,2,3)_{\mathrm{it}}=\alpha_{0}+\alpha_{1} \operatorname{lnINV} \_\mathrm{NUM}_{\mathrm{it}}+\alpha_{2} \mathrm{INTL}_{\mathrm{it}}+\alpha_{4} \mathrm{GY} \mathrm{Y}_{\mathrm{it}}+\varepsilon_{\mathrm{it}}
$$


In Eq. (1), lnPAT(1,2,3) represents three logarithmic measures of patent quality: backward citations (1), claims (2), and forward citations (3). InINV_NUM is simply the number of listed inventors while INTL is a $(0,1)$ dummy which distinguishes between patents with only domestic inventors (0), i.e., those with domestic addresses, and those with one or more international participants (1), i.e. those reporting a foreign address. If, for example, Apple, Inc. employs American nationals to work in the R\&D lab in a facility in China where that individual participates in the production of a patent that is filed in the USPTO, those inventors would be represented as inventors who are a part of China's domestic innovation system, not that of the United States. Hence the geographic location of the invention activity, not the inventor's nationality is the defining factor. Finally, GY represents the Grant Year, which we include only in the forward citation regression for the purpose of controlling for the time-dependent truncated distribution of forward citations.

We report the results of the Poisson regressions in Table 7, in which the upper panel reports the results for the 1975-2015 sample of U.S. patents. We first note the consistency of the estimates across the three measures of product quality. For the number of inventors, the estimates all fall in the range of 0.21 to 0.55 and are highly statistically robust. ${ }^{2}$ Given the counts shown for backward citations (Table 4) and claims (Table 6), the estimated elasticities in Table 5 imply substantial proportional quality gains ensuing from, say, a doubling of the number of inventors. For backward citations, in recent years, such increases are likely to result in double digit increases in the numbers of backward citations. For claims, the estimated elasticity of 0.21 implies increases of 3-4 claims per patent.

The results for international collaboration are strikingly different. These three sets of estimates are all negative and robustly so. The somewhat unexpected implication is that for U.S, patent production, when inventor collaboration extends abroad, the quality of the granted U.S. patent declines. We address this anomaly in Section 8.

The lower panel reports the counterpart results for China. Given China's unique circumstance in which the major portion of its USPTO patents are post-2000, thus severely limiting the number of forward citations, we give less weight to the forward citations estimate results for China. Consistent with this caveat, the one notable outlier for the China results is the

\footnotetext{
${ }^{2}$ Note that we regularly report t-statistics rather than standard errors or $p$-values, since given the magnitudes, the latter would in many cases simply appear as a string of zeros.
} 
estimated impact of the number of inventors on forward citations, which shows as significantly negative in the last column of the lower panel of Table 7. As with the U.S., the estimates for backward citations and claims are robustly positive but of smaller magnitudes than those reported for the U.S. This suggests that domestic inventor collaboration bears less advantage for Chinese patent production than for the U.S.

The largest and most striking difference between the U.S. and China is the impact of international collaboration on patent quality. Whereas we find that internationalization of patent research tends to diminish the quality of U.S. patent awards, for China the effect is to improve substantially patent quality. This categorical variable shows up consistently for all three of the quality measures. Again, in Section 8, we speculate on the possible reasons for these disparate results for the U.S. and China.

Hall et al (2005) find significant differences across technology sectors in the implications of R\&D and patent quality for firm performance. Acknowledging these differences, we have selected four specific technology categories for which we test for the specific impacts of inventor collaboration on patent quality. The regression analysis for the four sectors - automobiles, pharmaceuticals, semi-conductors, and solar - are shown in Table 8.

Comparing the U.S. and China results, we see that taken together the four technology groups yield results that are broadly consistent with the aggregate results in Table 7, with some variation. In all four cases, the results show estimates for the quality benefits of domestic collaboration that are greater for the U.S. than for China. Conversely, for international collaboration, the quality benefits are consistently larger for China than for the U.S. For the U.S. in two cases - automobiles and pharmaceuticals - the benefits are negative; for solar, the quality benefits are insignificant; only semi-conductors show any quality advantage for international inventor collaboration, and even then the point estimate is small.

For China, in all four technology sectors, international inventor collaboration bears significant gains. Even for semi-conductors, for which the U.S. exhibits some positive gain from international collaboration, the gain afforded to China is ten times as great as the U.S. gain.

Summarizing, we find that across our sample, domestic inventor collaboration yields quality benefits for home country patent production. The magnitudes and robustness of such benefits, however, vary significantly and consistently across China and the U.S. Such collaboration within the U.S. yields relatively generous payoffs; when such collaboration is 
extended to international inventors, however, the U.S. enjoys less benefit, which both in the aggregate and for certain industries appears to lie in the negative range. For China, the benefits of domestic inventor collaboration are consistently less that for the U.S. Internationalizing such collaboration, however, yields clear benefits to China in the aggregate; across specific industries, China's gains lie consistently within the range of $0.22-0.38$, i.e., a gain of about one-third or approximately four claims based on the averages shown in Table 5.

\section{Joint Assignee Ownership}

Paralleling and building on the previous section, in this section, we analyze the impact of configurations of patent assignee ownership. Using Eq. (2) below, we evaluate the impact of both domestic joint patent assignee ownership and the internationalization of such ownership on patent quality. To do this, we initially use the same functional form as that we used to analyze the implications of inventor collaboration:

$$
\operatorname{lnPAT}(1,2,3)_{\mathrm{it}}=\alpha_{0}+\alpha_{1} \ln \mathrm{ASG} \mathrm{NUM}_{\mathrm{it}}+\alpha_{2} \mathrm{INTL}_{\mathrm{it}}+\alpha_{4} \mathrm{GY}_{\mathrm{it}}+\varepsilon_{\mathrm{it}}
$$

The results, shown in Table 9, parallel those for inventors with some significant differences. For the U.S., while not robust for forward citations, greater numbers of assignees are otherwise associated with enhanced patent quality. With the exception of backward citations for which the addition of a foreign assignee tends to enhance patent quality, as with inventor status, the addition of a foreign assignee depresses patent quality.

In the case of China, the addition of domestic assignees has more mixed results than the gain resulting from additional inventors. Whereas for the latter, more domestic inventors increase the quality of patents in terms of backward citations and claims, the addition of inventors tends to diminish the count of forward citations, even after we attempt to control for the time structure of forward citations. By comparison, for assignees, an increase in their domestic numbers depresses patent quality as measured by the number of citations, backward and forward; only leaving claims with a positive response. As with the internationalization of inventors, the internationalization of assignees for Chinese patents tends to positively affect patent quality. Nonetheless, the effect is more ambiguous than it is for inventors. While the 
estimates for citations, both backward and forward, are positive and robust, the estimate for claims, although positive is statistically significant only at the $10 \%$ level. More notable, the magnitudes of the estimates across the three quality measures are strikingly different, ranging from only 0.009 and 0.043 for claims and backward citations to 0.459 for forward citations. Once again, given the paucity of forward citations for the large majority of more recentlygranted Chinese patents, we assign less weight to this last result and concluded that for China, the internationalization of patent assignees results in only marginal gains in patent quality.

In conclusion, our findings show notably different implications of inventor and assignee collaborative for China as compared with the U.S. For the U.S., the patent quality impacts of domestic inventor collaboration are consistency robust and positive. For China, the implications are mixed and consistently less robust than for the U.S. By comparison, whereas for the U.S. international inventor collaboration is associated with lower patent quality, for China such international collaboration is robustly associated with positive patenting outcomes. These results are largely confirmed with tests using four specific industries for which all of the domestic inventor collaboration results are more positive for the U.S. than for the counterpart Chinese estimates. Likewise, for international inventor collaboration, all of the Chinese estimates are significantly more positive than the counterpart U.S. estimates.

The consequences of assignee status show similar patterns as those of inventor profiles. Whereas, the number of assignees is consistently positively associated with patent quality for the U.S., for China, only the claims-quality association is positive, while that for backward and forward citations is robustly negative. By comparison, for the U.S. the inclusion of an international assignee has largely negative patent quality consequences; for China, the implications tend to be more neutral or positive.

The fact that the USPTO requires and publishes data on the organizations with which the patent assignees are affiliated at the time of submission of the patent applications enables us to extend our analysis into an intriguing dimension. That is, not only are we able to identify the impact of multiple assignees on patent quality, but knowing the organizational affiliation of each of the assignees, we are able to evaluate the impact of specific types of organizations (i.e., corporations, universities, and research institutes) and configurations of these organizations (e.g., more than one corporation or a university-research institute collaboration) on patent quality. Hence we use the following regression set up to assess the impact of various configurations of 
organizational ownership collaboration on a salient measure of patent quality, the number of claims granted by the USPTO.

$$
\begin{aligned}
& \operatorname{lnPATCL} \mathrm{it}_{i t}=\alpha_{0}+\alpha_{1} \ln \mathrm{ASG}_{-} \mathrm{NUM}_{\mathrm{it}}+\alpha_{2} \mathrm{CORP}_{\mathrm{it}}+\alpha_{3} \mathrm{UNIV}_{\text {it }}+\alpha_{4} \mathrm{RI}_{\mathrm{it}} \alpha_{2} \mathrm{~N} \\
& +\alpha_{5} \mathrm{CORP}^{*} \mathrm{UNIV}_{\mathrm{it}}+\alpha_{6} \mathrm{CORP} * \mathrm{RI}_{\mathrm{it}}+\alpha_{7} \mathrm{UNIV}^{*} \mathrm{RI}_{\mathrm{it}}+\alpha_{8} \mathrm{CORP}^{*} \mathrm{UNIV}^{*} \mathrm{RI}_{\mathrm{it}} \\
& +\alpha_{9} \mathrm{INTL}_{\mathrm{it}}+\alpha_{10} \mathrm{GY}_{\mathrm{it}}+\varepsilon_{\mathrm{it}}
\end{aligned}
$$

The results are shown in Table 10. There the numbers in patents next to U.S. (18) and China (12) represent the average number of claims each country has been awarded per patent over the sample period 2010-2015.

According to the results in Table 10, additions to the number of domestic assignees show rather different results for each country. These are large and robustly positive for the U.S. and significantly smaller and less robust for China. The result for the addition of one or more international assignees is somewhat similar to that shown previously in Table 9. That is, international collaboration is unambiguously negative for the U.S. and positive for China.

The U.S.-China country columns show different implications for the impact of organizational configurations on the claim count. For the U.S., the ordering from low- to highquality augmentation is: corporation(s) only, university-research institute, research institute(s) only, corporation-university, corporation-research institute, university (only), and corporationuniversity-and- research institute. For China, the ranking is somewhat different and spread out, with corporate-research institute and corporate-university topping the collaboration-quality gains. The puzzle for China is that that whereas the corporate-RI and corporate-university collaborations exhibit the largest positive impacts on patent quality, at the same time, the university-research institute and corporation-university-research institute (Triple Helix) configurations, exhibit the poorest quality outcomes, notwithstanding the fact that each of the configurations includes at least one university. We examine this puzzle in Section 8.

\section{Assignee-Inventor Relationship: Does it Matter?}

Having identified somewhat different responses of patent quality to the numbers of inventors and assignees and the international status of such inventors and assignees, we seek to 
determine the significance of variances in the ratios of assignees and inventors. We let $\mathrm{X}=$ the number of assignees and $\mathrm{Y}=$ the number of inventors. The question is whether there is an $\mathrm{X} / \mathrm{Y}$ effect? Below, we trace out two possibilities.

The first is the incentive effect. With this effect, the knowledge that if the patent is granted, the inventor will also enjoy assignee status endows the inventor with greater determination and effort to become a partner in producing a high-quality patent. Under this condition, we would anticipate the coefficient on assignee-inventor ratio to lie in the range $0<$ $\mathrm{X} / \mathrm{Y} \leq 1$. The alternative hypothesis is the coordination-scale effect in which sole or concentrated ownership enables a scaling up of R\&D capabilities. In this case, we anticipate the coefficient to be negative, i.e., $\mathrm{X} / \mathrm{Y}<1$, such that larger numbers of inventors in relation to owner-assignees are associated with higher quality patenting outcomes.

In Table 11, we report the results for claims and backward and forward citations. We implement the test for three categories of assignee/inventor ratio. The first is $X / Y=1 / 1=1$, a simple-one-to-one ratio in which the inventor and assignee are typically the same person; we reference these observations as UNIT. The second general case is that of a single assignee with multiple inventors; these observations are referenced as YPLUS. Finally, the third case is that in there are both multiple assignees and inventors. Such cases are referenced as XYPLUS. The regression that we implement, for backward citations, claims and forward citations, is:

$$
\operatorname{lnPAT}(1,2,3)_{\mathrm{it}}=\alpha_{0}+\alpha_{1} \mathrm{UNIT}_{\mathrm{it}}+\alpha_{2} \text { YPLUS }_{\mathrm{it}}+\alpha_{4} \mathrm{XYPLUS}_{\mathrm{it}}+\alpha_{5} \mathrm{GY}_{\mathrm{it}}+\varepsilon_{\mathrm{it}}
$$

in which UNIT is a dummy variable and YPLUS and XYPLUS are continuous variables. We estimate Eq. (4) for the full populations of U.S. and Chinese patents as well as for three subgroups within each country: the subsamples of corporations, universities, and research institutes.

Table 11 reports only the estimated coefficients for UNIT (1/1), YPLUS (1/y, y>1), and XYPLUS (x/y, x\&y>1). As shown by the asterisks (*) all but four of the 72 estimates are highly statistically significant. As shown for the U.S. portion of Table 11, estimates for the first group one assignee; one inventor - are consistently negative for claims and backward and forward citations, both overall and for each of the three categories of patent-producing organizations. These results imply that relative to the reference, which is that of $x=y>1$, i.e., an equivalent 
number of multiple inventors and assignees, the sole-inventor, sole-assigneee patents are of comparatively low quality.

Estimates of YPLUS and XYPLUS also yield negative results with a single exception that is the statistically insignificant impact on the number of claims of multiple assignees and multiple inventors for the sample of research institutes. In conclusion, the results for the U.S. offer virtually unanimous support for the coordination-scale hypothesis over the incentive hypothesis. That is, the larger the number of inventors relative to the number of assignees, the greater the coordination-scale effect, the greater the patent quality.

China offers a somewhat different set of results. For backward citations, as with the U.S., all of the overall and corporation estimates are significantly negative. However, unlike the U.S. results, those for universities and research institutes are split between significantly negative and significantly positive. The results are similar for claims with all of the U.S., estimates, save that for research institutes-forward citations, being significantly negative. For China's universities and research institutes, only two of the six estimates are significantly negative. Finally, for forward citations, whereas all of the estimates for the U.S. show significantly negative estimates, across-the-board for China, i.e., all but one of the 12 estimates is non-negative.

While our data for forward citations is somewhat limited, these results strongly suggest that the coordination-scale hypothesis dominates U.S. patent production. The more inventors relative to a given number of assignees, the higher the quality of the patent.

For China, apart from the forward-citation results, the overall and corporation results suggest a similar dominance of the coordination-scale claim. The key difference between the results is the set of results for Chinese universities and research institutes. Among the 12 estimates shown in the last two columns of Table 11, we see that nine are positive; only three are negative. These results imply that the incentive factor may be more important for Chinese universities and research institutes than for Chinese corporations and, still more so, for their U.S. research counterparts. Chinese universities and research institutes appear to rely more on incentivizing their associated inventors with the prospect of assignee ownership than other research entities.

\section{Interpretation}


It is instructive to refocus on the results in Table 8 regarding the different, somewhat curious, implications of domestic and international inventor collaboration for both the U.S. and China. For both, we note a tendency for an inverse relationship between the quality impacts of domestic and international collaboration. For the U.S. all four industries report gains in patent claims associated with domestic collaboration. However, the two industries for which domestic inventor teamwork is most statistically robust - automobiles and pharmaceuticals - are also those in which international collaboration is associated with the greatest reduction in claims. Semi-conductions, the only industry for which international collaboration yields any advantage for the U.S., is also the industry that yields the smallest quality gain from domestic collaboration. Understandably, the returns to domestic collaboration and those from international collaboration are likely to be inversely related.

For China, the results are equally as striking. For two industries - pharmaceuticals and semi-conductors - domestic inventor teamwork is associated with negative quality outcomes. Patenting in these same two industries is associated with the largest quality gains resulting from international inventor collaboration. Automobiles and solar, the remaining two industries for which domestic collaboration is most robust, both achieve positive, if comparatively modest, gains from international collaboration. Seemingly, for China, these inverse relationships between the quality implications of domestic and international collaboration reflect the relative position of China's industry technologies in relation to their respective international technology frontiers. For automobiles, the most robust of the domestic collaboration results, the participation of most of the major international automobile producers within Chinese majority-owned joint ventures is very likely to result in a distinct domestic inventor collaboration advantage for this industry. By comparison, the relative technology and research leadership of the U.S. likely accounts for the fact that for all four industries, U.S. gains from international research collaboration are consistently less than the counterpart gains for China.

A second notable puzzle that emerges from our research is that shown in Table 10, in which the estimates show positive and robust results for all forms of U.S. organizational collaboration, with the largest point estimate gain associated with so-called Triple Helix collaboration involving corporations, universities, and research institutes. By contrast, the counterpart estimate for China, as well as that for university-research institute collaboration is negative, if not highly significantly so. What might account for this lackluster result from the 
pairing of universities and research institutes with or without the participation of corporations? We first note that for the U.S., university-research institute collaborations yield the least gain among the various organizational collaborations. At this point, we can only advance several speculative possibilities.

We first recall the work of Maietta (2015) and who suggests that the expected returns from university-industry collaboration may be reduced, because university scholars may actively collaborate with firms only on topics that are relevant for their academic career advancement. Although the elevated returns to corporation-university returns belie this finding for China, the mix of university-research institute participation may introduce sufficient poorly-aligned idiosyncratic motivation to depress the scope of claims resulting joint ownership.

Notwithstanding, our China results for university-research institute and the triadic Triple Helix collaborations, the U.S. appears to perform exceptionally well in securing quality gains when corporations engage with universities and research institutes. This disparity between the U.S. and Chinese outcomes may reflect a variety of conditions specific to China that warrant further study as the record for China's Triple Helix patent results accumulate. Candidate explanations include: i) the participating corporations are largely state-owned enterprises that are less adept at coordinating inter-organizational research, ii) University-research institute collaborations and Triple Helix projects are the subject of government-sponsored R\&D subsidies that are ineffective or still of an experimental nature, iii) overall, such extensive organizational collaborations are relatively novel in China and require a period of learning-by-doing, and iv) the fields in which such collaborations are occurring or being encouraged in China are those in which the incidence of claims is typically fewer than average. Again, the record and data base needs to be substantially augmented in order to sort through these candidate hypotheses. The frame of our research methodology will be suitable for this investigation once the data accumulates.

A final issue that begs attention is the matter of the causal relationship between patent quality and the number of inventors and assignees that are associated with a patent grant. In this paper, we assume that patent quality is a result of the configuration of inventors and assignees. That is, one can imagine that the potential quality of a patent grant is a random, exogenouslydetermined datum, i.e., the promise of solving a particular problem of codifying a novel idea. The quality of the actual granted patent depends on the outcome of the research effort, which, in 
turn, is determined by the number of inventors and assignees engaged in producing the patent. Hence, given a patent's potential quality and the probability function relating probability outcomes to various configurations of inventor and assignee assignments, the chosen configuration of inventor-assignee inputs determines the quality of the resulting patent outcome. Although we assume that the choice of inventor collaboration and owner-assignee status significantly affects the quality of approved patents, the finding of systematic associations between various configurations of inventor and assignee participation is of substantial interest for the respective innovation systems of the U.S. and China.

\section{Conclusions and Next Steps}

Over the past 15 years, China has established a significant and growing international patenting presence. Although in 2015, among USPTO granted patents, China accounted for only $5 \%$ of the granted patents, this number, 7,450, grew dramatically from just 95 in 2000.

Furthermore, during 2016, the number of granted Chinese patents grew by $29.8 \%$, substantially faster than the $3.7 \%$ growth achieved by the U.S. and $9.3 \%$ achieved by S. Korea, the country receiving the second fastest growing number of USPTO patent grants.

Using the USPTO data set, we find that in terms of measures of patent quality - the number of claims and citations, both forward and backward - both U.S. and Chinese patent quality is significantly affected by inventor collaboration but to different degrees. For the U.S., returns to domestic collaboration are large and significant; by comparison, the returns to international collaboration are not positive and at times negative.

By comparison, for China, the contribution to patent quality of domestic collaboration is uneven; overall it is of far less advantage than that for U.S. patents. In contrast with the U.S., quality returns to international collaboration for China are consistently large and significant. When we examine the quality implications of joint assignee status, we find similar results relative to the U.S., lesser quality gains to Chinese patents accruing from domestic joint assignee ownership and more advantage associated with shared international assignee ownership.

One of the more interesting findings and promising avenues of this research is the relationship between inventor collaboration and joint assignee ownership. A central finding is that in the U.S., the likelihood of inventors also becoming assignees is relatively limited, 
particularly in the corporate sector. We attribute this to the coordination-scale effect, that is, a single assignee may be able to mobilize the participation of a substantial number of inventors without incentivizing them by sharing assignee status. In China, the situation differs. There we find higher assignee-inventor ratio as associated with higher quality patents, particularly for universities and research institutes, thus suggesting a different circumstance at work; that is the need to incentivize inventors with by sharing the assignment of patent ownership. That this condition is less evident in the corporate sector in both China and the U.S. may reflect a practice of corporations of employing basic compensation, including bonuses, to reward successful inventors, while the corporation retains sole ownership of the patent. By contrast, more liquidity constrained, universities and research institutes may be more inclined to enable a sharing of patent ownership as a means of incentivizing inventors and providing compensation commensurate with their contributions as successful inventors.

\section{References}

Ankrah, S., \& AL-Tabbaab, O. (2015). Universities-industry collaboration: A systematic review. Scandinavian Journal of Management, 31(3), 387-408.

Etzkowitz, H., \& Leydesdorff, L. (2000). The dynamics of innovation: from National Systems and "Mode 2" to a Triple Helix of university-industry-government relations. Research Policy, 29(2), 109-123.

Leydesdorff, Loet, 2012. "The Triple Helix of University-Industry-Government Relations," University of Amsterdam, Amsterdam School of Communication Research (ASCoR), Kloveniersburgwal 48, 1012 CX Amsterdam, The Netherlands.

Hall, B. H., Jaffe, A. B., \& Trajtenberg, M. (2005). Market value and patent citations. Rand Journal of Economics, 36(1), 16-38.

Hall, B. H., Jaffe, A. B., \& Trajtenberg, M. (2001) The NBER patent citations data file: Lessons, insights and methodological tools. National Bureau of Economic Research, Working Paper 8498 http://www.nber.org/papers/w8498.

Jaffe, A. B., \& de Rassenfosse, G. (2017). Patent citation data in social science research: Overview and best practices. Journal of the Association for Information Science and Technology, http://onlinelibrary.wiley.com/doi/10.1002/asi.23731/abstract

Maietta, O.W. (2015). Determinants of university-firm R\&D collaboration and its impact on innovation: a perspective from a low-tech industry. Research Policy, 44(7), 1341-1359. 
Mowry, David and Bhaven Sampat, 2009, Universities in National Innovation Systems, Oxford Handbooks Online, ed. Jan Fagenberg and David Mowry,

http://www.oxfordhandbooks.com/view/10.1093/oxfordhb/9780199286805.001.0001/oxfordhb$\underline{9780199286805-e-8}$

Soh, P., \& Subramanian, A. M. (2014). When do firms benefit from university-industry R\&D collaborations? The implications of firm R\&D focus on scientific research and technological recombination. Journal of Business Venturing, 29(6), 807-821.

SONG Hefa1, LI Zhenxing, 2014. "Patent quality and the measuring indicator system:

Comparison among China provinces and key countries," Institute of Policy and Management, Chinese Academy of Sciences, Beijing, P.R.C, 100190

Wuchty, S., Jones, B. F., \& Uzzi, B. (2007). The Increasing Dominance of Teams in Production of Knowledge. Science, 316(5827), 1036-1039. 
Table 1. Comparing USPTO and SIPO (2015)

\begin{tabular}{|l|c|c|c|c|c|}
\hline & $\begin{array}{c}\text { USPTO } \\
\text { (Granted } \\
\text { patents) }\end{array}$ & $\begin{array}{c}\text { SIPO } \\
\text { (Patent } \\
\text { applications }\end{array}$ & $\begin{array}{c}\text { SIPO } \\
\text { (Granted } \\
\text { patents) }\end{array}$ & US patents & $\begin{array}{c}\text { Chinese } \\
\text { patents }\end{array}$ \\
\hline $\begin{array}{l}\text { Number of } \\
\text { patents }\end{array}$ & 325,980 & $2,798,500$ & $1,718,192$ & n.a. & n.a. \\
\hline $\begin{array}{l}\text { top tier } \\
\text { patents \% }\end{array}$ & 91.5 & 39.4 & 20.9 & n.a. & n.a. \\
\hline $\begin{array}{l}\text { international } \\
\text { patents \% }\end{array}$ & $\begin{array}{c}49.8 \% \\
\text { (inventor } \\
\text { country) } \\
55.1 \% \\
\text { (assignee } \\
\text { country) }\end{array}$ & $\begin{array}{c}5.7 \% \text { (total } \\
\text { patent) } \\
12.1 \% \\
\text { (invention } \\
\text { patent) }\end{array}$ & $\begin{array}{c}7.1 \% \text { (total } \\
\text { patent) } \\
\text { (invention } \\
\text { patent) }\end{array}$ & n.a. & n.a. \\
\hline $\begin{array}{l}\% \text { with inter- } \\
\text { national } \\
\text { inventor }\end{array}$ & n.a. & n.a. & n.a. & $10.4 \%$ & $24.8 \%$ \\
\hline $\begin{array}{l}\% \text { with inter- } \\
\text { national } \\
\text { assignee }\end{array}$ & n.a. & n.a. & n.a. & $1.0 \%$ & $12.9 \%$ \\
\hline
\end{tabular}

Table 2. Patent counts (USPTO)

2015: U.S. $=146,883 ;$ non-U.S. $=142,981$

\begin{tabular}{|l|c|c|c|c|}
\hline Year & 1990 & 2000 & 2010 & 2015 \\
\hline China & 26 & 95 & 2,355 & 7,450 \\
\hline U.S. & 37,536 & 80,313 & 109,152 & 146,883 \\
\hline Japan & 18,898 & 32,787 & 47,731 & 55,110 \\
\hline S. Korea & 163 & 3,285 & 12,519 & 20,305 \\
\hline Germany & 6,520 & 9,530 & 12,431 & 16,220 \\
\hline Other EU & 7,508 & 12,725 & 17,933 & 27,801 \\
\hline
\end{tabular}


Table 3 . Research \& ownership collaboration, 1975-05 vs. 2006-15

\begin{tabular}{|l|l|c|c|c|c|}
\hline & & $\begin{array}{c}\text { \# of } \\
\text { inventors }\end{array}$ & $\begin{array}{c}\text { share with } \\
\text { inventor } \\
\text { international } \\
\text { collaboration (\%) }\end{array}$ & $\begin{array}{c}\text { \# of assignee } \\
\text { organizations }\end{array}$ & $\begin{array}{c}\text { share with } \\
\text { assignee } \\
\text { international } \\
\text { collaboration (\%) }\end{array}$ \\
\hline \multirow{3}{*}{ U.S. } & $1975-2005$ & 1.977 & 3.369 & 1.005 & 0.388 \\
\cline { 2 - 6 } & $2006-2015$ & 2.676 & 8.585 & 1.022 & 0.963 \\
\hline \multirow{3}{*}{ Japan } & $1975-2005$ & 2.678 & 1.805 & 1.03 & 0.652 \\
\cline { 2 - 7 } & $2006-2015$ & 2.613 & 2.998 & 1.069 & 1.216 \\
\hline \multirow{3}{*}{ China } & $1975-2005$ & 2.426 & 30.573 & 1.096 & 3.063 \\
\cline { 2 - 7 } & $2006-2015$ & 2.945 & 30.106 & 1.327 & 27.28 \\
\hline \multirow{2}{*}{ S. Korea } & $1975-2005$ & 2.091 & 3.721 & 1.013 & 0.617 \\
\cline { 2 - 7 } & $2006-2015$ & 3.024 & 4.163 & 1.049 & 0.947 \\
\hline \multirow{2}{*}{ Germany } & $1975-2005$ & 2.433 & 8.757 & 1.009 & 0.639 \\
\cline { 2 - 7 } & $2006-2015$ & 2.908 & 19.955 & 1.037 & 2.06 \\
\hline \multirow{2}{*}{ Other EU } & $1975-2005$ & 2.119 & 10.668 & 1.015 & 0.827 \\
\cline { 2 - 7 } & $2006-2015$ & 2.721 & 22.709 & 1.058 & 2.537 \\
\hline
\end{tabular}


Table 4. Average number of backward citations

\begin{tabular}{|l|c|c|c|c|}
\hline & 1990 & 2000 & 2010 & 2015 \\
\hline China & 5.81 & 6.83 & 12.37 & 14.63 \\
\hline U.S. & 8.96 & 13.04 & 41.85 & 56.95 \\
\hline Japan & 5.42 & 6.51 & 17.14 & 21.42 \\
\hline S. Korea & 4.74 & 6.62 & 16.72 & 17.88 \\
\hline Germany & 5.36 & 5.57 & 18.52 & 24.23 \\
\hline Other EU & 5.82 & 6.61 & 21.72 & 25.09 \\
\hline
\end{tabular}

Table 5. Average number of claims

\begin{tabular}{|l|c|c|c|c|}
\hline & 1990 & 2000 & 2010 & 2015 \\
\hline China & 11.73 & 9.29 & 12.22 & 12.42 \\
\hline U.S. & 14.31 & 17.49 & 18.08 & 17.61 \\
\hline Japan & 10.25 & 13.81 & 11.70 & 11.42 \\
\hline S. Korea & 8.60 & 12.97 & 14.52 & 13.26 \\
\hline Germany & 11.44 & 13.22 & 15.28 & 14.56 \\
\hline Other EU & 10.83 & 14.22 & 15.83 & 15.25 \\
\hline
\end{tabular}


Table 6. Average number of forward citations

\begin{tabular}{|l|c|c|c|c|}
\hline & 1990 & 2000 & 2010 & 2015 \\
\hline China & 20.96 & 6.67 & 3.20 & n.a. \\
\hline U.S. & 23.57 & 27.20 & 5.74 & n.a. \\
\hline Japan & 14.99 & 14.46 & 2.59 & n.a. \\
\hline S. Korea & 10.73 & 13.05 & 3.06 & n.a. \\
\hline Germany & 10.65 & 10.51 & 2.74 & n.a. \\
\hline Other EU & 12.93 & 13.45 & 3.42 & n.a. \\
\hline
\end{tabular}

Table 7. Role of Inventor Status in Patent Quality, 1975-2015

\begin{tabular}{|c|c|c|c|}
\hline & $\begin{array}{c}\text { Backward } \\
\text { citations }\end{array}$ & Claims & $\begin{array}{l}\text { Forward } \\
\text { citations }\end{array}$ \\
\hline \multicolumn{4}{|c|}{ U.S. } \\
\hline $\ln$ (INV_NUM) & $\begin{array}{c}0.551 \\
(3006.07)\end{array}$ & $\begin{array}{c}0.212 \\
(903.20)\end{array}$ & $\begin{array}{c}0.302 \\
(1146.47)\end{array}$ \\
\hline INT'L & $\begin{array}{c}-0.075 \\
(162.66)\end{array}$ & $\begin{array}{l}-0.027 \\
(44.49)\end{array}$ & $\begin{array}{c}-0.278 \\
(355.18)\end{array}$ \\
\hline Granted years & n.a. & n.a. & $\begin{array}{c}0.036 \\
(2776.83)\end{array}$ \\
\hline Constant & $\begin{array}{c}2.791 \\
\left(1.5 \times 10^{4}\right)\end{array}$ & $\begin{array}{c}2.633 \\
\left(1.2 \times 10^{4}\right)\end{array}$ & $\begin{array}{c}1.894 \\
(5132.06) \\
\end{array}$ \\
\hline Obs. & $3,079,353$ & $3,078,307$ & $3,079,353$ \\
\hline Adj R-sq & 0.053 & 0.020 & 0.075 \\
\hline \multicolumn{4}{|c|}{ China } \\
\hline $\ln (\mathrm{INV}$ _NUM $)$ & $\begin{array}{c}0.212 \\
(125.70)\end{array}$ & $\begin{array}{c}0.216 \\
(113.92)\end{array}$ & $\begin{array}{l}-0.126 \\
(29.13)\end{array}$ \\
\hline INT'L & $\begin{array}{c}0.389 \\
(172.64)\end{array}$ & $\begin{array}{c}0.119 \\
(45.31)\end{array}$ & $\begin{array}{c}0.456 \\
(79.05)\end{array}$ \\
\hline Granted years & n.a. & n.a. & $\begin{array}{c}0.139 \\
(440.07)\end{array}$ \\
\hline Constant & $\begin{array}{c}2.459 \\
(1340.60)\end{array}$ & $\begin{array}{c}2.281 \\
(1121.37)\end{array}$ & $\begin{array}{c}0.204 \\
(41.95)\end{array}$ \\
\hline Obs. & 60,219 & 60,219 & 60,219 \\
\hline Adj R-sq & 0.049 & 0.035 & 0.233 \\
\hline
\end{tabular}


Table 8. Impact of Inventor Collaboration on Patent Claims

\begin{tabular}{|l|c|c|c|c|}
\hline & \multicolumn{2}{|c|}{ Automobiles - claims } & \multicolumn{2}{c|}{ Pharmaceuticals - claims } \\
\hline & US & China & US & China \\
\hline Ln_INVNUM & 0.195 & 0.127 & 0.148 & -0.011 \\
& $(122.69)$ & $(7.31)$ & $(130.61)$ & $(1.11)$ \\
\hline INT'L & -0.046 & 0.218 & -0.061 & 0.376 \\
& $(9.82)$ & $(8.71)$ & $(25.56)$ & $(26.62)$ \\
\hline Constant & 2.642 & 2.425 & 2.712 & 2.508 \\
& $(2030.37)$ & $(141.86)$ & $(2092.99)$ & $(175.96)$ \\
\hline Obs. & 73,313 & 702 & 108,519 & 1,558 \\
\hline Pseudo R2 & 0.018 & 0.035 & 0.011 & 0.042 \\
\hline & Semiconductor - claims & \multicolumn{2}{|c|}{ Solar - claims } \\
\hline & US & China & US & China \\
\hline Ln_INVNUM & 0.014 & -0.057 & 1.709 & 0.047 \\
& $(8.03)$ & $(3.96)$ & $(32.88)$ & $(2.35)$ \\
\hline INT'L & 0.031 & 0.301 & 0.061 & 0.231 \\
& $(8.32)$ & $(16.36)$ & $(0.17)$ & $(8.21)$ \\
\hline Constant & 2.810 & 2.636 & 14.370 & 2.660 \\
& $(1663.49)$ & $(177.09)$ & $(110.54)$ & $(97.97)$ \\
\hline Obs. & 54,296 & 1,118 & 33,746 & 348 \\
\hline Pseudo R2 & 0.000 & 0.029 & 0.033 & 0.026 \\
\hline
\end{tabular}


Table 9. Role of Assignee Status in Patent Quality

\begin{tabular}{|c|c|c|c|}
\hline & $\begin{array}{c}\text { Backward } \\
\text { citations }\end{array}$ & Claims & $\begin{array}{l}\text { Forward } \\
\text { citations }\end{array}$ \\
\hline \multicolumn{4}{|c|}{ U.S. } \\
\hline $\ln \left(\mathrm{ASSG} \_\mathrm{NUM}\right)$ & $\begin{array}{c}0.243 \\
(138.30) \\
\end{array}$ & $\begin{array}{c}0.233 \\
(105.30)\end{array}$ & $\begin{array}{l}0.007 \\
(2.50)\end{array}$ \\
\hline INT'L & $\begin{array}{c}0.053 \\
(28.23) \\
\end{array}$ & $\begin{array}{l}-0.061 \\
(25.00)\end{array}$ & $\begin{array}{l}-0.192 \\
(56.82) \\
\end{array}$ \\
\hline Granted years & n.a. & n.a. & $\begin{array}{c}0.035 \\
(2578.27)\end{array}$ \\
\hline constant & $\begin{array}{c}3.261 \\
\left(\mathbf{2 . 6 \times 1 0 ^ { 4 }}\right)\end{array}$ & $\begin{array}{c}2.816 \\
\left(1.8 \times 10^{4}\right)\end{array}$ & $\begin{array}{c}2.123 \\
(7018.26)\end{array}$ \\
\hline Obs. & $2,549,905$ & $2,549,384$ & $2,549,905$ \\
\hline Adj R-sq & 0.0003 & 0.0004 & 0.071 \\
\hline \multicolumn{4}{|c|}{ China } \\
\hline $\ln \left(\mathrm{ASSG} \_\mathrm{NUM}\right)$ & $\begin{array}{l}-0.229 \\
(23.26)\end{array}$ & $\begin{array}{c}0.181 \\
(19.36)\end{array}$ & $\begin{array}{l}-0.312 \\
(10.60)\end{array}$ \\
\hline INT'L & $\begin{array}{l}0.043 \\
(5.79) \\
\end{array}$ & $\begin{array}{l}0.009 \\
(1.30)\end{array}$ & $\begin{array}{c}0.459 \\
(21.29) \\
\end{array}$ \\
\hline Granted years & n.a. & n.a. & $\begin{array}{c}0.156 \\
(308.63) \\
\end{array}$ \\
\hline constant & $\begin{array}{c}2.628 \\
(1514.76) \\
\end{array}$ & $\begin{array}{c}2.428 \\
(1266.48)\end{array}$ & $\begin{array}{l}-0.195 \\
(29.25)\end{array}$ \\
\hline Obs. & 34,485 & 34,485 & 34,485 \\
\hline Adj R-sq & 0.003 & 0.005 & 0.238 \\
\hline
\end{tabular}


Table 10. Impact of Ownership Assignment (Assignees) on Patent Quality (claims)

\begin{tabular}{|c|c|c|}
\hline & U.S. (18)* & China (12)* \\
\hline Constant & $\begin{array}{c}2.712 \\
(3978.13)\end{array}$ & $\begin{array}{c}2.374 \\
(222.01)\end{array}$ \\
\hline $\ln \mathrm{ASSG}$ NUM & $\begin{array}{c}0.189 \\
(71.44)\end{array}$ & $\begin{array}{l}0.046 \\
(4.20)\end{array}$ \\
\hline Corp & $\begin{array}{c}0.105 \\
(151.13)\end{array}$ & $\begin{array}{l}0.041 \\
(3.74) \\
\end{array}$ \\
\hline Univ & $\begin{array}{c}0.205 \\
(183.16)\end{array}$ & $\begin{array}{c}0.150 \\
(11.55)\end{array}$ \\
\hline RI & $\begin{array}{c}0.163 \\
(140.43)\end{array}$ & $\begin{array}{c}0.169 \\
(12.71)\end{array}$ \\
\hline Corp*Univ & $\begin{array}{c}0.171 \\
(47.08)\end{array}$ & $\begin{array}{c}0.279 \\
(21.08)\end{array}$ \\
\hline Corp*RI & $\begin{array}{c}0.176 \\
(34.83)\end{array}$ & $\begin{array}{c}0.296 \\
(17.19)\end{array}$ \\
\hline Univ*RI & $\begin{array}{c}0.118 \\
(19.72)\end{array}$ & $\begin{array}{r}-0.077 \\
(1.68)\end{array}$ \\
\hline Corp*Univ*RI & $\begin{array}{c}0.307 \\
(21.72)\end{array}$ & $\begin{array}{l}-0.049 \\
(0.60)\end{array}$ \\
\hline INT'L & $\begin{array}{l}-0.042 \\
(16.70)\end{array}$ & $\begin{array}{c}0.085 \\
(11.02)\end{array}$ \\
\hline Obs. & $2,549,384$ & 34,485 \\
\hline R-sq & 0.002 & 0.010 \\
\hline
\end{tabular}


Table 11. Impact of assignee/inventor ratios on patent quality (1975-2015)

\begin{tabular}{|c|c|c|c|c|}
\hline \multicolumn{5}{|c|}{ U.S. } \\
\hline & Overall & Corporations & Universities & $\begin{array}{l}\text { Research } \\
\text { institutes }\end{array}$ \\
\hline \multicolumn{5}{|l|}{ Backward } \\
\hline $1 / 1$ & $-0.422 * * *$ & $-0.441 * * *$ & $-0.222 * * *$ & $-0.261 * * *$ \\
\hline $1 / \mathrm{y}, \mathrm{y}>1$ & $-0.632 * * *$ & $-0.627 * * *$ & $-0.466^{* * *}$ & $-0.510 * * *$ \\
\hline$x / y, x \& y>1$ & $-0.261 * * *$ & -0.236 *** & -0.267 *** & $-0.398 * * *$ \\
\hline \multicolumn{5}{|l|}{ Claims } \\
\hline $1 / 1$ & $-0.172 * * *$ & $-0.169 * * *$ & $-0.087 * * *$ & $-0.121 * * *$ \\
\hline $1 / y, y>1$ & $-0.156^{* * *}$ & $-0.155^{* * *}$ & $-0.110^{* * *}$ & $-0.122 * * *$ \\
\hline $\mathrm{x} / \mathrm{y}, \mathrm{x} \& \mathrm{y}>1$ & $-0.079 * * *$ & $-0.073 * * *$ & $-0.060 * * *$ & 0.002 \\
\hline \multicolumn{5}{|l|}{ Forward } \\
\hline $1 / 1$ & $-0.237 * * *$ & $-0.240 * * *$ & $-0.142 * * *$ & $-0.223 * * *$ \\
\hline $1 / y, y>1$ & -0.378 *** & $-0.385^{* * *}$ & $-0.357 * * *$ & $-0.422 * * *$ \\
\hline $\mathrm{x} / \mathrm{y}, \mathrm{x} \& \mathrm{y}>1$ & $-0.183 * * *$ & $-0.143 * * *$ & $-0.313 * * *$ & $-0.513 * * *$ \\
\hline \multicolumn{5}{|c|}{ China } \\
\hline \multicolumn{5}{|l|}{ Backward } \\
\hline $1 / 1$ & $0.014 * * *$ & $-0.015 * * *$ & $-0.421 * * *$ & $-0.091 * * *$ \\
\hline $1 / y, y>1$ & $-0.045^{* * *}$ & $-0.172 * * *$ & $0.063 * * *$ & $0.234 * * *$ \\
\hline $\mathrm{x} / \mathrm{y}, \mathrm{x} \& \mathrm{y}>1$ & $-0.314 * * *$ & $-0.346^{* * *}$ & $0.169 * * *$ & $-0.151 * * *$ \\
\hline \multicolumn{5}{|l|}{ Claims } \\
\hline $1 / 1$ & $-0.341 * * *$ & $-0.360 * * *$ & $-0.159 * * *$ & $0.129 * * *$ \\
\hline $1 / y, y>1$ & $-0.019 * * *$ & $-0.089 * * *$ & $0.296 * * *$ & $0.157 * * *$ \\
\hline$x / y, x \& y>1$ & $-0.087 * * *$ & $-0.098 * * *$ & 0.022 & $-0.137 * * *$ \\
\hline \multicolumn{5}{|l|}{ Forward } \\
\hline $1 / 1$ & $0.267 * * *$ & $0.162 * * *$ & $0.506^{* * *}$ & 0.055 \\
\hline $1 / y, y>1$ & $0.442 * * *$ & $0.431 * * *$ & 0.002 & $0.436^{* * *}$ \\
\hline $\mathrm{x} / \mathrm{y}, \mathrm{x} \& \mathrm{y}>1$ & $0.187 * * *$ & $0.179 * * *$ & $-0.137 * * *$ & $0.291 * * *$ \\
\hline
\end{tabular}

Note: the forward regression has controlled the granted years. $* * *(* * *)$ indicates statistical significance at the $1 \%(5 \%, 10 \%)$ level. 
Figure 1. Distribution of Backward Citations

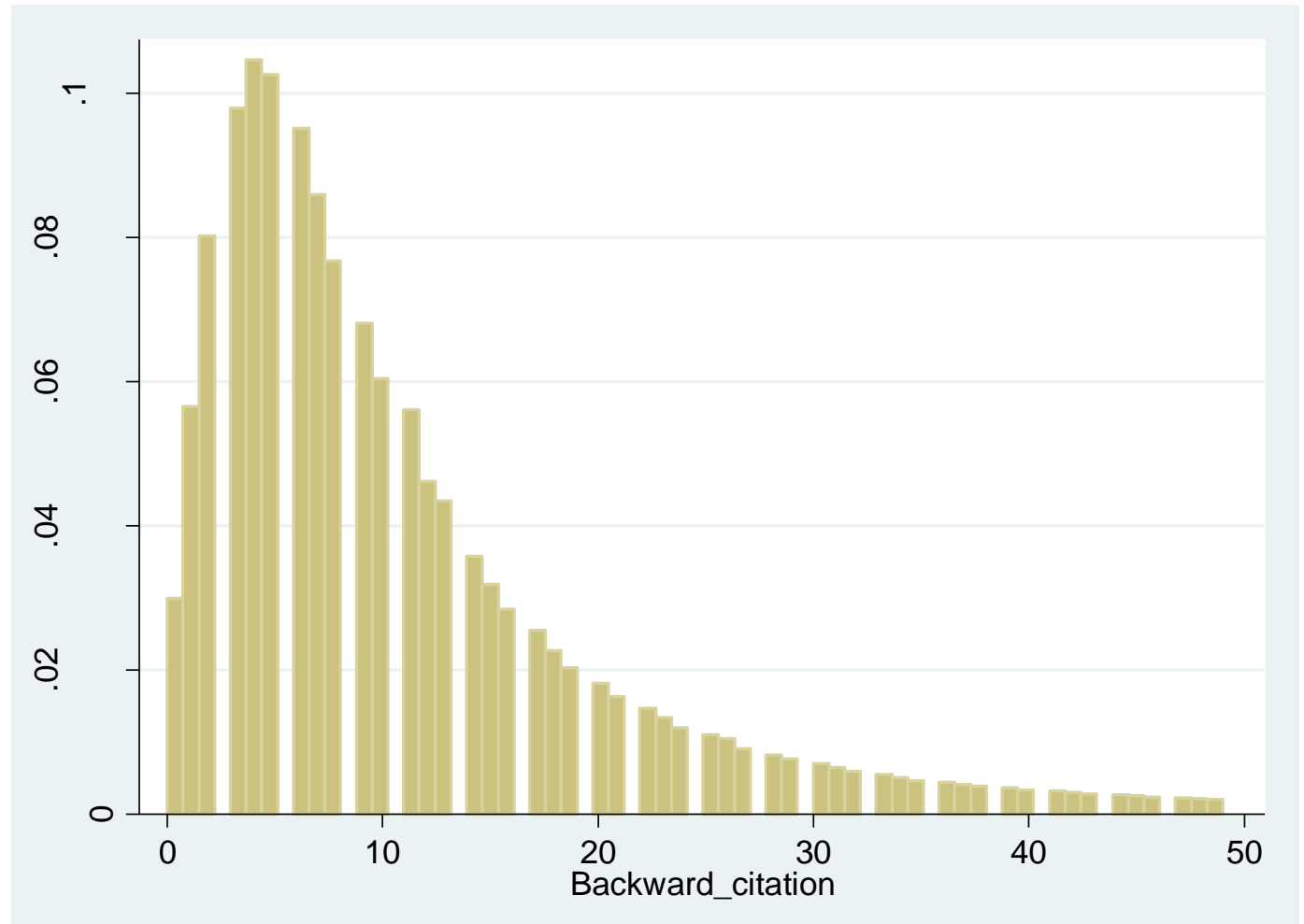

Figure 2. Distribution of Claims

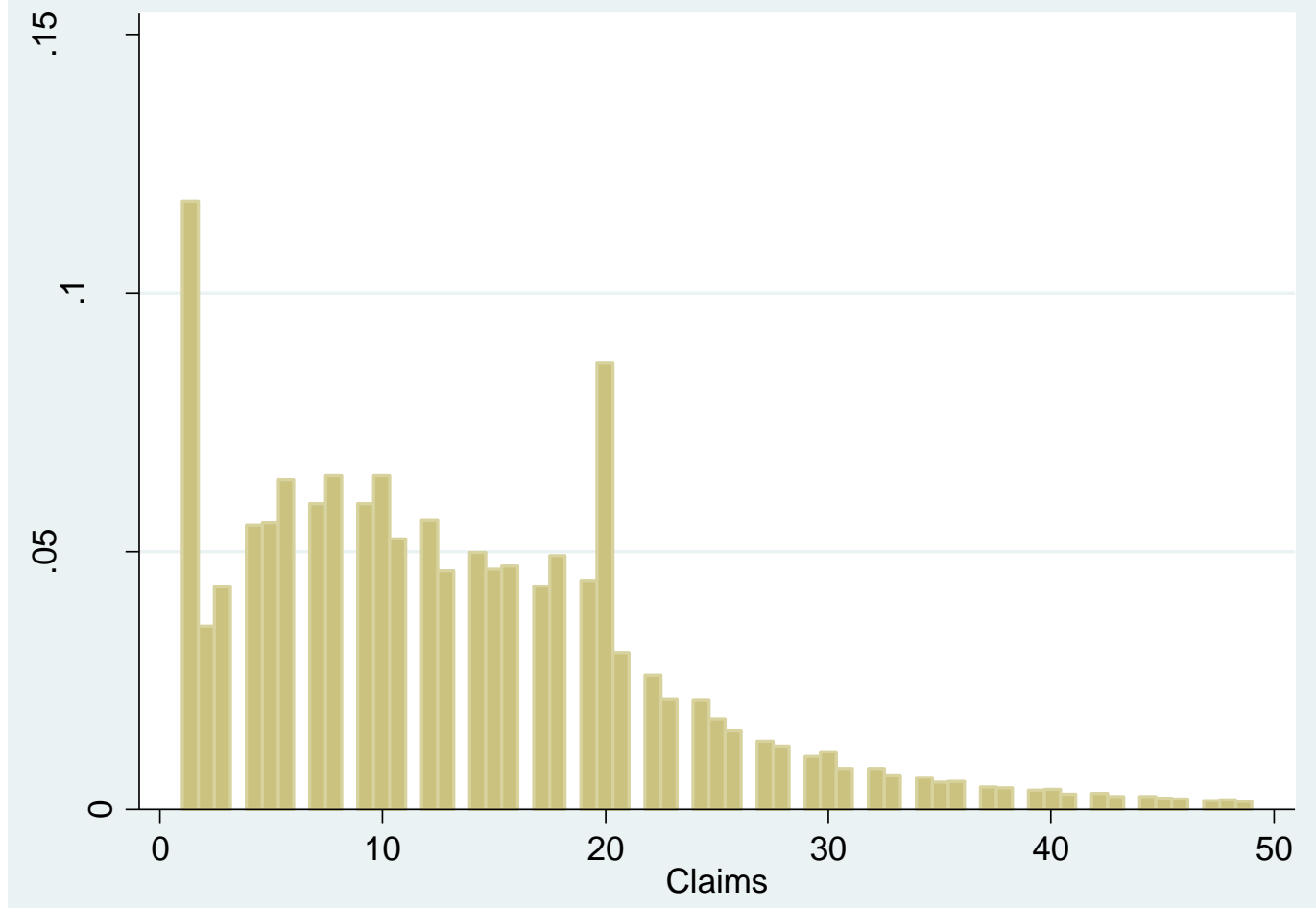


Figure 3. Distribution of Forward Citations

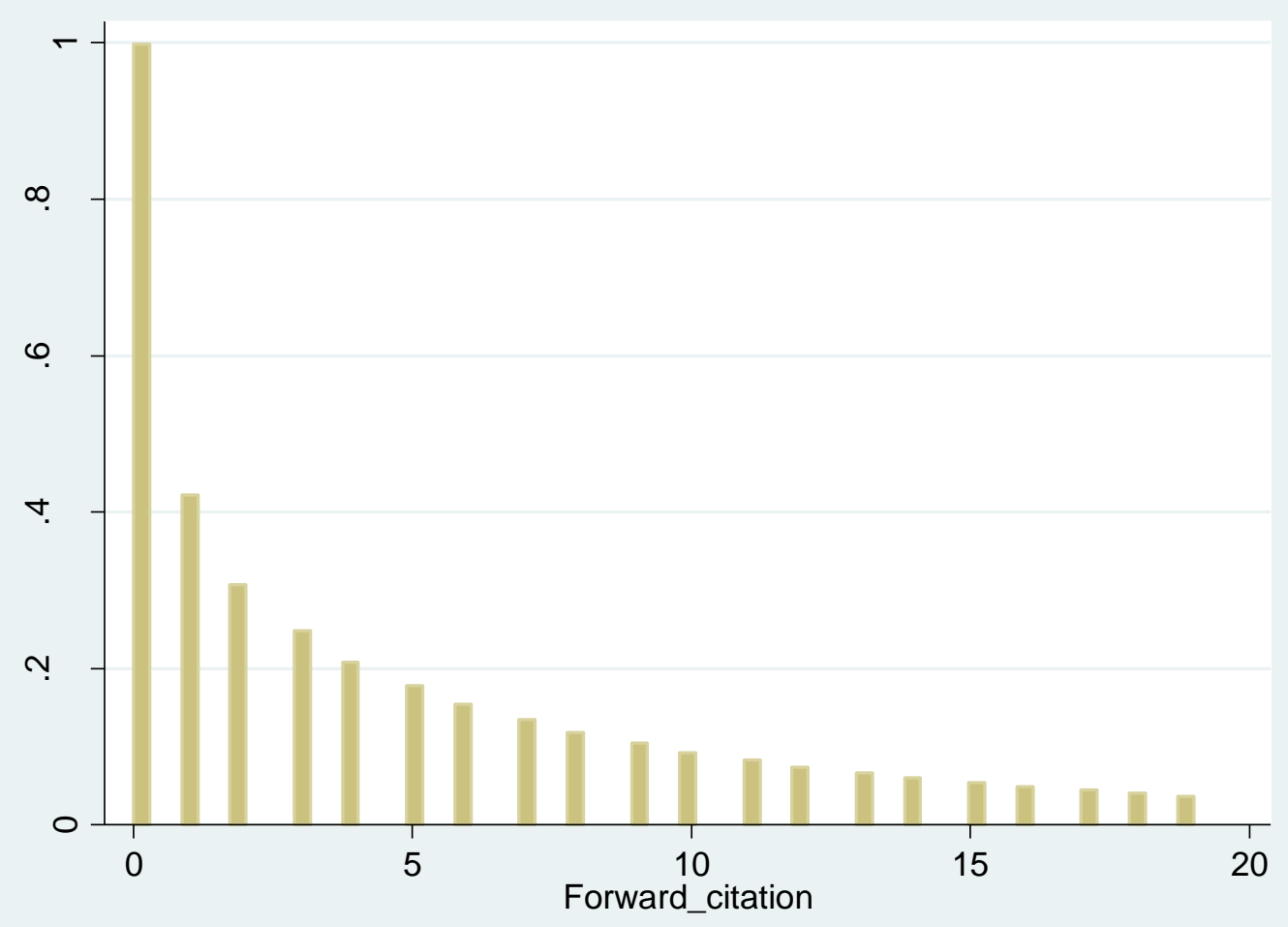

